\title{
BMJ Open Secondhand tobacco smoke exposure and pulmonary function: a cross- sectional study among non-smoking employees of bar and restaurants in Santiago, Chile
}

Javiera Parro, ${ }^{1}$ Paulina Aceituno, ${ }^{2}$ Andrea Droppelmann, ${ }^{3}$ Sthepanie Mesías, ${ }^{2}$ Claudio Muñoz, ${ }^{4}$ Nella Marchetti, ${ }^{5}$ Verónica Iglesias ${ }^{2}$

To cite: Parro J, Aceituno P, Droppelmann A, et al. Secondhand tobacco smoke exposure and pulmonary function: a cross-sectional study among non-smoking employees of bar and restaurants in Santiago, Chile. BMJ Open 2017;7:e017811. doi:10.1136/ bmjopen-2017-017811

- Prepublication history for this paper is available online. To view these files, please visit the journal online (http://dx.doi. org/10.1136/bmjopen-2017017811).

Received 19 May 2017 Revised 24 August 2017 Accepted 31 August 2017

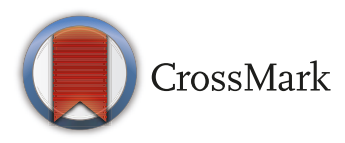

For numbered affiliations see end of article.

Correspondence to Dr Verónica Iglesias; viglesia@med.uchile.cl

\section{ABSTRACT}

Introduction The workplace remains a significant source of secondhand smoke (SHS) exposure. This pollutant is known to be associated with respiratory and cardiovascular problems, but its effects on specific pulmonary function parameters remain largely unexplored. The objectives of this study were to measure SHS exposure among non-smoking employees of bar and restaurants in Santiago, Chile and to evaluate the effects of such exposure on pulmonary function.

Methods Cross-sectional design. The study sample included non-smoking workers from 57 restaurants and bars in Santiago, Chile. The outcome variable was pulmonary function and the exposure variables were urine cotinine concentration, a biomarker for current SHS exposure, and years of SHS exposure in the workplace as proxy of chronic exposure. Personal and occupational variables were also recorded. Data analysis was performed using linear regression models adjusted by confounders. Results The median age of the workers was 35 years and the median employment duration at the analysed venues was 1 year. Workers in smoking facilities reported greater SHS exposure (36hours per week) than workers in smoke-free locations (4 hours per week). Urine cotinine levels were inversely correlated with forced vital capacity, but the finding was not statistically significant $(\beta=-0.0002 ; 95 \% \mathrm{Cl}-0.007$ to 0.006$)$. Years of exposure to SHS showed to be significantly associated with forced expiratory flow ${ }_{25 / 75}(\beta=-0.006 ; 95 \% \mathrm{Cl}-0.010$ to $-0.0004)$.

Conclusion These findings suggest that cumulative exposure to SHS at work may contribute to deterioration of pulmonary function in non-smoking employees.

\section{INTRODUCTION}

The secondhand smoke (SHS) is the smoke that remains in the air after someone has consumed tobacco, including the smoke coming from the burning end of the cigarette (side-stream smoke) and the smoke exhaled by the smoker (mainstream smoke). ${ }^{1-5}$ Sidestream smoke contains higher concentration
Strengths and limitations of this study

- The effects of occupational secondhand smoke (SHS) exposure on specific pulmonary function parameters has been scarcely explored.

- This study is the first in Chile to evaluate occupational SHS exposure and its association with specific pulmonary function parameters.

- The use of the variable 'number of years exposed to SHS at workplace' was appropriate to study chronic SHS exposure.

- Our sample included mainly young workers being reasonable to infer that the employees did not accumulate enough years of SHS exposure to register greater changes in pulmonary function.

- Daily fluctuations of the timing of the spirometry measurements may have affected the results, since these were performed at different times of day, according to the availability and shifts of the workers and establishments.

of harmful substances than main stream as it contains a greater amount of toxic gases and smaller particles that reach greater depth in the lungs when inhaled. ${ }^{6}$ SHS is a common indoor pollutant in restaurants and bars that poses a serious health risk for non-smokers as it contains over 50 substances known to be carcinogenic in humans. ${ }^{78}$ There is no known safe exposure level. ${ }^{14}$ Some of the highest and most sustained occupational exposure to SHS occur in bar staff, with non-smoking areas providing only limited protection. ${ }^{9}$

SHS exposure can lead to the same health problems associated with active smoking, ${ }^{178}$ with risk levels increasing as a function of hours of exposure. ${ }^{10-14}$ Common scenarios associated with chronic SHS exposure include living with a spouse or parent who smokes and working in a location where smoking is allowed. $^{35}$ Previous studies have not been 
consistent in showing a decline in specific pulmonary function parameters in people affected by SHS exposure at work or at home. ${ }^{915-20}$ This lack of evidence may be attributable to the methods use to measure SHS exposure, which range from self-report to measurement of exposure biomarkers. ${ }^{15-19}$

One of the most common ways of measuring SHS exposure is measuring concentration of cotinine, the principle metabolite of nicotine. Cotinine can be measured in the blood or urine and shows high sensitivity and specificity for acute SHS exposure (over the past 3-4 days), although some authors have also used it to evaluate longer term exposure. ${ }^{21-23}$ Chronic exposure to SHS has been measured through questionnaire and by hair nicotine concentration. ${ }^{2425}$

In 2010, the time at which this study was performed, Chilean law prohibited tobacco smoking in public areas and workplaces. However, there were exceptions for 'hospitality' venues, such as casinos, bars, pubs, restaurants and cafés. Bars, pubs and restaurants with areas smaller than $100 \mathrm{~m}^{2}$ could choose to allow smoking indoors or not, while facilities with an area larger than $100 \mathrm{~m}^{2}$ were required to offer separate sections for smokers and non-smokers. Therefore, 'hospitality' workers were unprotected from SHS exposure, becoming the workplace, in many cases, the main source of SHS exposure. $^{2627}$

The objectives of this study were to measure SHS exposure among non-smoking workers in restaurants and bars in Santiago, Chile and to evaluate the effects of such exposure on pulmonary function.

\section{METHODS}

This cross-sectional study was performed as part of a larger project, 'Impact of involuntary exposure to tobacco smoke on respiratory health: study of pub and restaurant workers', carried out in Santiago, Chile between September 2010 and January 2011. This study was approved by the University of Chile School of Medicine's Ethics Committee.

\section{Population and sample}

The selection process for participating facilities has been previously described in detail. ${ }^{28}$ In brief, the sampling framework included the five municipalities with the largest numbers of facilities, according to data provided by the National Institute of Statistics (in Spanish, Instituto Nacional de Estadísticas). Study staff visited 690 locations and used a brief survey to record the venue's name, address, type of facility (bar/pub, restaurant or other), smoking status (smoking allowed in all areas; designated smoking/non-smoking areas or smoke free) and number of non-smoking workers. Of the 690 facilities, 207 met inclusion criteria (be a bar-pub or restaurant and have non-smoking workers). Of them, 108 were visited or contacted by telephone to invite the owner or manager to participate in the study. In 63 establishments they agreed to participate $(58 \%)$. For logistical reasons, only 59 of the facilities were included. ${ }^{28}$ Smoking and non-smoking workers in these facilities were invited to participate in the main study. Only those who had not smoked in the last year were included in the current study. Workers were excluded if they did not provide a urine sample $(n=5)$ or had a contraindication for spirometry $(n=1) .{ }^{29} 30$

\section{Outcome variables}

Pulmonary function parameters: Certified personnel used an Easy One Diagnostic to measure forced vital capacity $(\mathrm{FVC})$ and forced expiratory volume in $1 \mathrm{~s}\left(\mathrm{FEV}_{1}\right)$, and then calculated the $\mathrm{FEV}_{1}$ to $\mathrm{FVC}$ ratio $\left(\mathrm{FEV}_{1} / \mathrm{FVC}\right)$ and forced expiratory flow (FEF) as $25 \% \%-75 \%$ of $\mathrm{FVC}$ $\left(\mathrm{FEF}_{25-75}\right)$. Spirometry measurements were performed during working hours. In compliance with international norms on collecting and interpreting spirometry data, age, sex, weight, height and race of each participant were also recorded. ${ }^{29} 30$ A maximum of eight spirometry trials were performed. The criteria for including a participant's spirometry data in the analysis was achieving at least three acceptable and two reproducible trials, as described in the norms published by Spanish Society of Pneumology and Thoracic Surgery (Sociedad Española de Neumología y Cirugía Torácica (SEPAR)). ${ }^{29} 30$ The equipment was calibrated weekly.

\section{Exposure variables}

Urine cotinine concentration. Each worker was asked to provide urine sample the morning after the spirometry measurements. The sample was provided, retrieved and frozen on the same day. Urine cotinine concentration was measured using ELISA at a sensitivity of $1 \mathrm{ng} / \mathrm{mL}$. The cut-off value typically used in the literature to distinguish smokers from non-smokers is $10 \mathrm{ng} / \mathrm{mL}^{31}$. As a quality control, duplicate samples were obtained and analysed. There was a strong correlation between the original and duplicate samples (Spearman's correlation $=0.96$; $\mathrm{p}$ value $=0.0005$ ) . Chronic exposure to SHS was measured as the number of years exposed to SHS at workplace (number of years worked at their three most recent job positions and whether it involved SHS exposure).

\section{Covariables}

The questionnaire included items about the participant's health history (asthma diagnosis, smoking habits); occupational history (job function at the facility, secondary employment at another facility, number of hours per day and days per week worked); occupational exposure (number of hours per day and days per week exposed to SHS) and the type of facility (smoking, mixed or non-smoking).

\section{Statistical analysis}

Data analysis was performed using the program STATA V.12. The quantitative variables were assessed for normality using the Shapiro-Wilk test. Descriptive statistics were calculated, including median and interquartile ranges $\left(\mathrm{P}_{25}-\mathrm{P}_{75}\right)$ for quantitative variables and relative 
frequency for qualitative variables. Quantitative exposure variables and covariables, such as number of hours per week of SHS exposure or age were dichotomised using the median as cut-off. Kruskal Wallis test and Wilcoxon test were used to assess difference of pulmonary parameters and exposure variables between the categories of the covariables. Finally, the association between pulmonary function parameters and exposure to SHS was analysed using multiple linear regression models adjusted by covariates potentially associated with both the outcome and the exposure considering a $p$ value of $<0.10^{32}$ and the variables commonly controlled for in the literature.

\section{RESULTS}

We evaluated 92 non-smoking workers. A $18.5 \%$ were excluded due to spirometry results failed to meet the criteria for acceptability and reproducibility. The final sample was 75 workers. Median age was 35 years $\left(\mathrm{P}_{25}{ }^{-}\right.$ $\mathrm{P}_{75} 19$ to 68 years) and $61 \%$ of participants were male. Former smokers were $29.3 \%$ and the median of time they quit smoking was 8.5 years $\left(\mathrm{P}_{25}-\mathrm{P}_{75} 2\right.$ to 15 years $)$. They were homogeneously distributed at the different facility type. On average, participants had worked at the studied venue for 12 months. Independent of the facility type, the sample was mainly composed of waiting staff, bartenders and cashiers $(70.7 \%)$. Workers in smoking facilities reported higher number of weekly hours exposed to SHS compared with workers in mixed and non-smoking facilities $(p$ value $=0.0001) \quad($ table 1$)$.

As shown in table 2, we compared the results for pulmonary function and exposure to SHS based on covariables. Men had greater pulmonary function values than women, except for $\mathrm{FEV}_{1} / \mathrm{FVC}$ ratio, where no differences were observed. No differences in pulmonary function were observed between former smokers and never smokers groups. In terms of the occupational exposure variables, employees working in the kitchen had lower values for $\mathrm{FVC}, \mathrm{FEV}_{1}$ and $\mathrm{FEF}_{25 / 75}$ than the group of wait staff, bartenders, cashiers and managers. Regarding the number of hours per week of SHS exposure and pulmonary function, exposure greater than 26 hours per week was associated with a $0.02 \%$ decrease in $\mathrm{FEV}_{1} / \mathrm{FVC}$ and a $230 \mathrm{~mL}$ decrease in $\mathrm{FEF}_{25 / 75}$, although these results were not statistically significant. Workers in smoking venues had $\mathrm{FEF}_{25 / 75} 400 \mathrm{~mL}$ lower and $\mathrm{FEV}_{1} / \mathrm{FVC}$ ratios $0.03 \%$ lower than those of workers in non-smoking venues. In terms of urine cotinine concentration, although differences were observed between categories of job function and the hours per week exposed to SHS, these differences were strongly influenced by workplace's smoking policy. For example, in the case of wait staff/bartenders/cashiers working in venues where smoking was allowed, they had

Table 1 Characteristics of the study sample (Santiago, Chile 2010-2011)

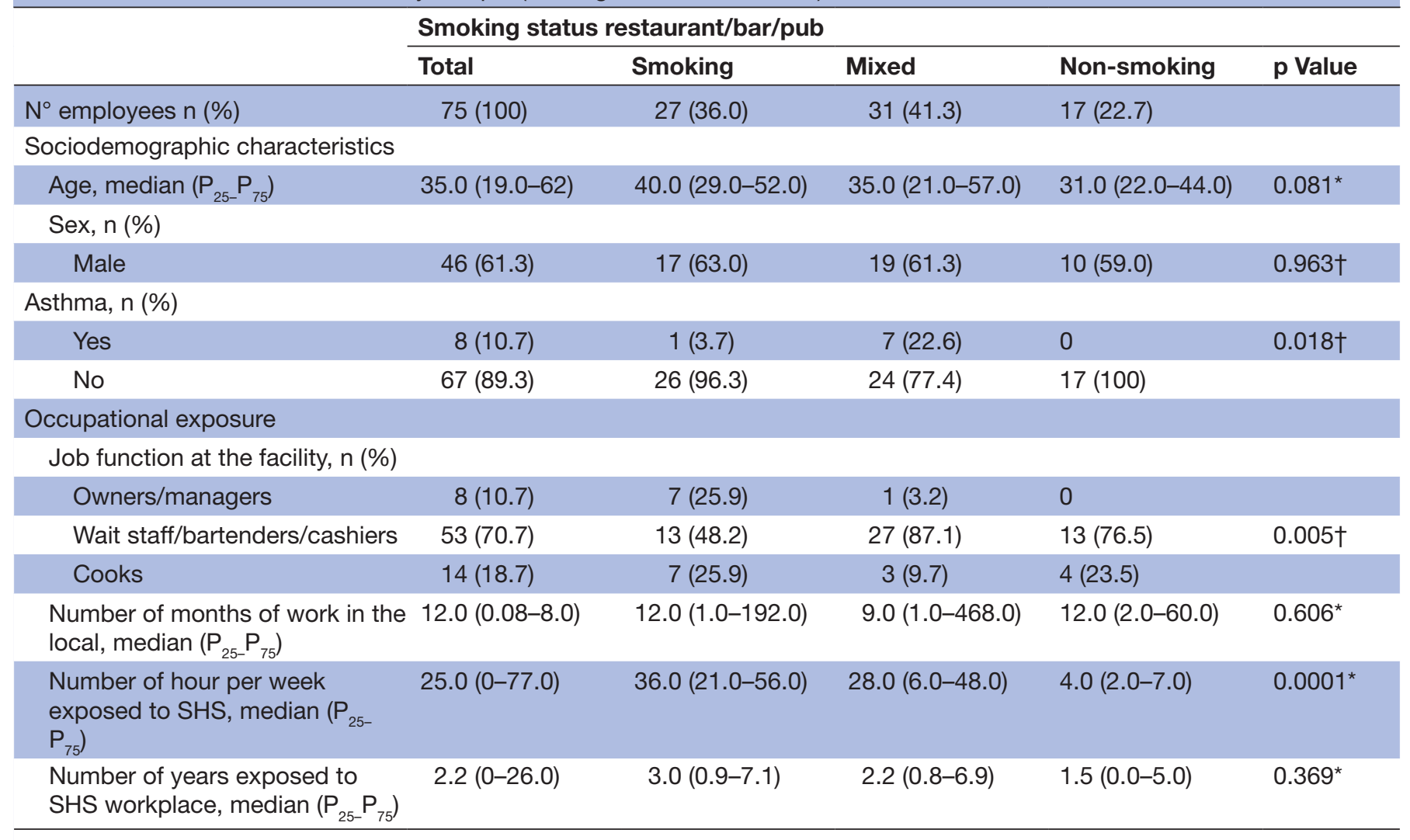

${ }^{*}$ Kruskal Wallis.

$\dagger \chi^{2}$.

SHS, secondhand smoke. 


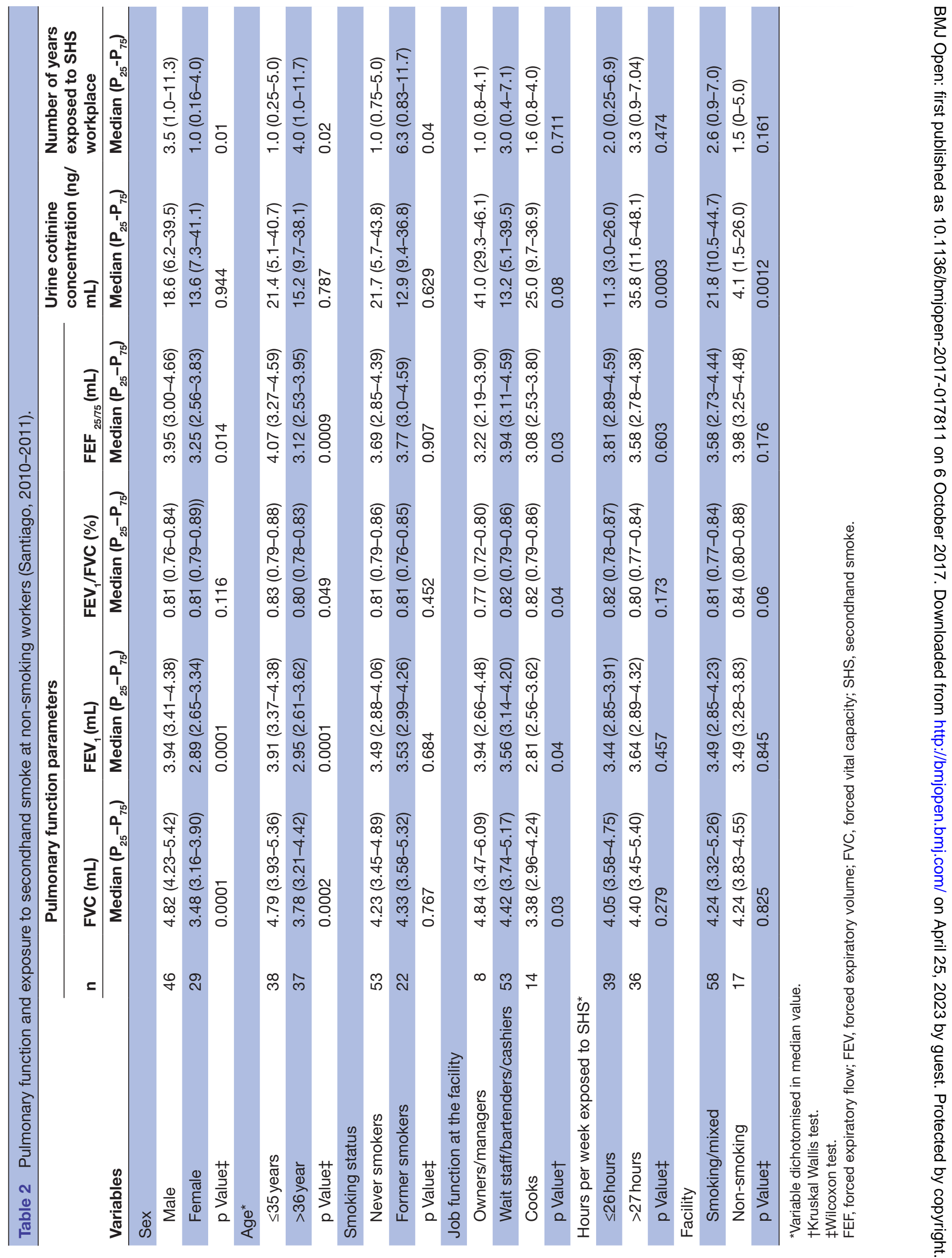


Table 3 Bivariate association of pulmonary function parameters in non-smokers workers according to covariables of interest

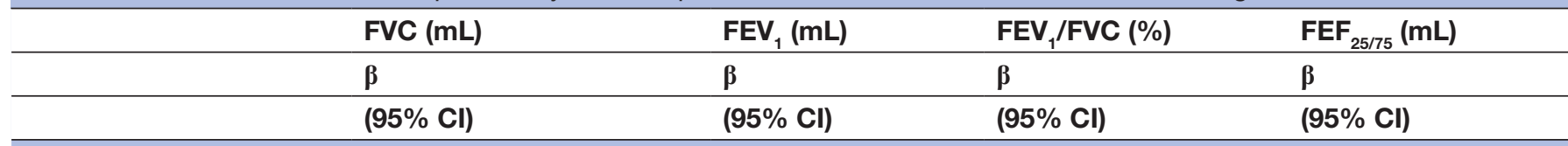

Sociodemographic variables

Sex

\begin{tabular}{|c|c|c|c|c|}
\hline \multirow[t]{2}{*}{ Male } & 1.26 & 0.91 & -0.03 & 0.61 \\
\hline & $(0.880$ to 1.650$)$ & (0.601 to 1.213$)$ & $(-0.064$ to -0.0003$)$ & (0.110 to 1.103$)$ \\
\hline \multicolumn{5}{|l|}{ Age } \\
\hline & -0.03 & -0.03 & -0.001 & -0.04 \\
\hline & $(-0.05$ to -0.02$)$ & $(-0.04$ to -0.02$)$ & $(-0.003$ to -0.003$)$ & $(-0.055$ to -0.019$)$ \\
\hline \multicolumn{5}{|l|}{ Weight } \\
\hline & 0.04 & 0.02 & -0.001 & 0.01 \\
\hline & (0.02 to 0.05$)$ & (0.01 to 0.04$)$ & $(-0.002$ to -0.0001$)$ & $(-0.004$ to 0.034$)$ \\
\hline \multicolumn{5}{|l|}{ Size } \\
\hline & 0.08 & 0.06 & -0.001 & 0.05 \\
\hline & $(0.07$ to 0.10$)$ & (0.050 to 0.074$)$ & $(-0.002$ to 0.001$)$ & (0.029 to 0.076$)$ \\
\hline \multicolumn{5}{|l|}{ Asthma } \\
\hline \multirow[t]{2}{*}{ Yes } & 0.04 & -0.17 & -0.05 & -0.67 \\
\hline & $(-0.731$ to 0.802$)$ & $(-0.750$ to 0.422$)$ & $(-0.100$ to -0.010$)$ & $(-1.470$ to 0.122$)$ \\
\hline \multicolumn{5}{|c|}{ Occupational exposure variables } \\
\hline \multicolumn{5}{|c|}{ Job function at the facility } \\
\hline \multicolumn{2}{|c|}{ Wait staff/bartenders/cashiers Reference } & Reference & Reference & Reference \\
\hline \multirow[t]{2}{*}{ Owners/managers } & 0.37 & 0.003 & -0.06 & -0.83 \\
\hline & $(-0.370$ to 1.110$)$ & $(-0.570$ to 0.570$)$ & $(-0.113$ to -0.021$)$ & $(-1.613$ to -0.047$)$ \\
\hline \multirow[t]{2}{*}{ Cooks } & -0.70 & -0.64 & -0.02 & -0.77 \\
\hline & $(-1.290$ to -0.120$)$ & $(-1.090$ to -0.190$)$ & $(-0.061$ to 0.022$)$ & $(-1.391$ to -0.151$)$ \\
\hline \multicolumn{5}{|c|}{ Hours per week exposed to SHS } \\
\hline & 0.01 & 0.01 & -0.0004 & 0.002 \\
\hline & (0.002 to 0.020$)$ & $(-0.0005$ to 0.014$)$ & $(-0.001$ to 0.0002$)$ & $(-0.008$ to 0.011$)$ \\
\hline \multicolumn{5}{|l|}{ Facility } \\
\hline Non-smoking & Reference & Reference & Reference & Reference \\
\hline \multirow[t]{2}{*}{ Smoking/mixed } & 0.10 & -0.05 & -0.03 & -0.41 \\
\hline & $(-0.460$ to 0.672$)$ & $(-0.486$ to 0.381$)$ & $(-0.071$ to 0.003$)$ & $(-1.003$ to 0.177$)$ \\
\hline
\end{tabular}

FEF, forced expiratory flow; FEV, forced expiratory volume; FVC, forced vital capacity.

a median urinary cotinine concentration of $40.7 \mathrm{ng} / \mathrm{mL}$. Employees working in mixed venues (with smoking and non-smoking areas) had a median of $13.5 \mathrm{ng} / \mathrm{mL}$ and those who working in smoke-free venues had a median of $2.5 \mathrm{ng} / \mathrm{mL}$. In the same way, the information regarding urinary cotinine concentration in people working over 27 hours per week exposed to SHS in venues where smoking was allowed was $45.2 \mathrm{ng} / \mathrm{mL}$, in those working in mixed venues the median was $13.6 \mathrm{ng} / \mathrm{mL}$ and in those working in smoke-free venues the median was $2.0 \mathrm{ng} / \mathrm{mL}$. The number of years exposed to SHS workplace varied according to sex, age and smoking status of employees.

Consistent with the literature, sex, age and weight were significantly associated with pulmonary function parameters (table 3$)$. In terms of job function, the owners and managers had $\mathrm{FEV}_{1} / \mathrm{FVC}$ values $60 \%$ lower and $\mathrm{FEF}_{25 / 75}$ values $830 \mathrm{~mL}$ lower than the group of wait staff, bartenders and cashiers. The kitchen workers had $700 \mathrm{~mL}$ lower FVC values, $640 \mathrm{~mL}$ lower $\mathrm{FEV}_{1}$ values and $772 \mathrm{~mL}$ lower $\mathrm{FEF}_{25 / 75}$ than the group of wait staff, bartenders and cashiers. Workers in smoking facilities had $413 \mathrm{~mL}$ lower $\mathrm{FEF}_{25 / 75}$ and $3 \%$ lower $\mathrm{FEV}_{1} / \mathrm{FVC}$ than workers in non-smoking venues.

Association between pulmonary function and SHS exposure The crude model revealed that the association between pulmonary function and urine cotinine concentration was not statistically significant (table 4 ). The multivariate 
Table 4 Crude and adjusted association between pulmonary function parameters and SHS exposure of non-smoking workers of bars and restaurants

\begin{tabular}{|c|c|c|c|c|c|c|c|c|}
\hline & \multicolumn{2}{|l|}{ FVC (mL) } & \multicolumn{2}{|l|}{ FEV $_{1}(\mathrm{~mL})$} & \multicolumn{2}{|l|}{ FEV $_{1} /$ FVC (\%) } & \multicolumn{2}{|l|}{ FEF25/75 (mL) } \\
\hline & $\boldsymbol{\beta}$ & \multirow[b]{2}{*}{$\mathbf{R}^{2}$} & $\beta$ & \multirow[b]{2}{*}{$\mathbf{R}^{2}$} & $\beta$ & \multirow[b]{2}{*}{$\mathbf{R}^{2}$} & $\beta$ & \multirow[b]{2}{*}{$\mathbf{R}^{2}$} \\
\hline & (95\% Cl) & & $(95 \% \mathrm{Cl})$ & & (95\% Cl) & & $(95 \% \mathrm{Cl})$ & \\
\hline \multicolumn{9}{|c|}{ Urine cotinine } \\
\hline \multirow{2}{*}{$\begin{array}{l}\text { Crude } \\
\text { model }\end{array}$} & 0.002 & 0.002 & 0.002 & 0.003 & 0.0002 & 0.002 & 0.002 & 0.002 \\
\hline & $(-0.010$ to 0.010$)$ & & $(-0.010$ to 0.010$)$ & & $(-0.001$ to 0.001$)$ & & $(-0.010$ to 0.010$)$ & \\
\hline \multirow[t]{2}{*}{$\begin{array}{l}\text { Adjusted } \\
\text { model }\end{array}$} & -0.0002 & 0.781 & 0.001 & 0.795 & 0.0004 & 0.33 & 0.005 & 0.672 \\
\hline & $(-0.007 \text { to } 0.006)^{*}$ & & $(-0.003 \text { to } 0.006)^{*}$ & & $(-0.0003$ to 0.001$) \dagger$ & & $(-0.006$ to 0.015$) \dagger$ & \\
\hline \multicolumn{9}{|c|}{ Number of years exposed to SHS at work } \\
\hline \multirow{2}{*}{$\begin{array}{l}\text { Crude } \\
\text { model }\end{array}$} & -0.025 & 0.046 & -0.022 & 0.061 & -0.0008 & 0.013 & -0.022 & 0.032 \\
\hline & $(-0.051$ to 0.002$)$ & & $(-0.042$ to -0.001$)$ & & $(-0.002$ to 0.0008$)$ & & $(-0.050$ to 0.006$)$ & \\
\hline \multirow[t]{2}{*}{$\begin{array}{l}\text { Adjusted } \\
\text { model }\end{array}$} & -0.013 & 0.79 & -0.01 & 0.802 & 0.0006 & 0.324 & -0.006 & 0.964 \\
\hline & $(-0.030 \text { to } 0.0025)^{*}$ & & $(-0.022 \text { to } 0.002)^{\star}$ & & $(-0.001$ to 0.002$) \dagger$ & & $(-0.010$ to -0.0004$) \dagger$ & \\
\hline
\end{tabular}

*Adjusted by sex, age, weight, size and job function at the facility.

†Adjusted by sex, age, size, asthma status and job function at the facility.

FEF, forced expiratory flow; FEV, forced expiratory volume; FVC, forced vital capacity.

analysis was based on a parsimonious model that included the covariate 'job function', as this variable was related to pulmonary function and urine cotinine concentration with a p value $<0.10$, as well as the variables sex, age, weight, height and asthma status, all of which are recognised as variables that affect pulmonary function according to SEPAR. ${ }^{29}{ }^{32}$ The adjusted model did not demonstrate a significant association between urine cotinine concentration and decreased pulmonary function. Conversely, the number of years of SHS exposure in workplace showed an inverse and significant association with $\mathrm{FEV}_{1}$. Each year of SHS exposure was associated with a $200 \mathrm{~mL}$ decrease in $\mathrm{FEV}_{1}(95 \% \mathrm{CI}-0.042$ to -0.001$)$. The other pulmonary function variables were also inversely associated with years of SHS exposure in workplace, although the association in these cases did not reach significance. The adjusted model showed an inverse and in some cases statistically significant association between the number of years of SHS exposure and pulmonary function parameters, specifically in $\mathrm{FEF}_{25 / 75}(\beta=-0.006 ; 95 \% \mathrm{CI}-0.010$ to $-0.0004)$.

\section{DISCUSSION}

This study is the first in Chile to evaluate occupational SHS exposure and its association with specific pulmonary function parameters. We did not find an inverse association between pulmonary function parameters and urine cotinine concentration, but when we considered number of years exposed to SHS in workplace, we found an inverse association with $\mathrm{FVC}, \mathrm{FEV}_{1}, \mathrm{FEV}_{1} / \mathrm{FVC}$ and $\mathrm{FEF}_{25 / 75}$ being significant only for the last parameter.
Similar findings were described by other researchers who reported a reduction in $\mathrm{FVC}$ and $\mathrm{FEF}_{25 / 75},{ }^{20} 33$ in $\mathrm{FVC},{ }^{15}$ in FVC and $\mathrm{FEV} 1{ }^{16}$ in subjects exposed to environmental tobacco smoke. In terms of job function, kitchen workers showed lower pulmonary function values than the group of wait staff, bartenders and cashiers as compared with the owners and managers. One possible explanation for these findings is that the SHS exposure had an additive effect with exposure to other pollutants emitted in the kitchen. In the literature has been reported that workers in kitchens with gas stoves show lower pulmonary function parameters than those in kitchens with electric stoves due to greater exposure to toxic substances in the air after cooking with gas. ${ }^{34}$ In our study, it was not possible to analyse differences according this variable because $100 \%$ of the establishments used gas stoves.

As noted above, we did not find a significant association between pulmonary function parameters and urine cotinine concentration. A possible explanation for these results is that urine cotinine levels reflect recent exposure to tobacco smoke ${ }^{21} 2231$ while chronic exposure to SHS is likely implicated in a decline in pulmonary function parameters. In fact, in table 4 we can see that the proportion of the variance $\left(R^{2}\right)$ explained by number of years of SHS exposure in workplace is greater than that explained by the current urine cotinine concentration, suggesting that this variable (number of years of SHS exposure) may be more appropriate when we are studying chronic effects. Other studies that have addressed this topic have produced varying results ${ }^{15-1720-223135}$ reported a significant inverse association between SHS exposure 
(evaluated through self-report) and FVC and $\mathrm{FEV}_{1}$. As in our study, Chen et al did not find a significant association when serum cotinine was assess as exposure variable but did when exposure to SHS was measured through self-report. ${ }^{16}$

Our results are not as strong as those described in other studies. ${ }^{12-142033}$ It should be noted that our sample included mainly young workers, being reasonable to infer that the sample not accumulated sufficient years of SHS exposure to register significant changes in pulmonary function. Also the median time worked at the location was only about 1 year. About $25 \%$ of the sample had worked at the given facility for less than 3 months, and $75 \%$ of the sample had worked at the location for fewer than 2 years. This condition of high turnover rate, along with the relative youth of the workers contributes to assume that the sample not accumulated enough years of SHS exposure to register significant changes in pulmonary function. A second limitation was that although all participants were non-smokers, those who worked in non-smoking venues reported be exposed to SHS at least 4 hours a week. Also in this group the median urine cotinine concentration was $4.1 \mathrm{ng} / \mathrm{mL}$. The lack of a true control group could have lead to underestimating the effect of SHS exposure. Another potential limitation was the timing of the spirometry measurements. The literature reports that pulmonary function varies throughout the day according to circadian rhythm, decreasing from a high point in the early morning until about noon, and then rising again to peak between about 4 and 5 in the afternoon. These daily fluctuations may have affected the results, as the lung function measurements were performed at different times of day, according to the availability and shifts of the workers and establishments. Finally, our small sample size along with the weak correlation between exposure to SHS and pulmonary function prevent us to have enough power to demonstrate a strongest association as shown in other studies.

Notwithstanding the above, our study shows that exposure to SHS among non-smoking employees working in venues where smoking is allowed appear to be substantially higher than those found in employees working in venues where smoking is not allow. The median urine cotinine in non-smoking employees working in a venue were smoking is allowed was $38.1 \mathrm{ng} / \mathrm{mL}$, in a mixed venue was $12.5 \mathrm{ng} / \mathrm{mL}$ and where smoking was not allowed was $4.1 \mathrm{ng} / \mathrm{mL}$. Given that SHS is a proven carcinogen in humans to which non-smoking workers of this type of venues are exposed involuntarily, a total smoking ban would provide a major protection to employees working in such venues.

\section{CONCLUSION}

The years of exposure to SHS in workplace as proxy of chronic exposure were inverse and significantly associated with the $\mathrm{FEF}_{25 / 75}$ and inverse but not significant with $\mathrm{FVC}$ and $\mathrm{FEV}_{1}$. These findings suggest that cumulative exposure to SHS at work may contribute to deterioration of pulmonary function in non-smoking employees.

Author affiliations

${ }^{1}$ Escuela de Enfermería, Universidad de Los Andes, Santiago, Chile

${ }^{2}$ Programa Epidemiología, Escuela de Salud Pública, Facultad de Medicina, Universidad de Chile, Santiago, Chile

${ }^{3}$ Laboratorio de Salud Ocupacional, Instituto de Salud Pública, Santiago, Chile ${ }^{4}$ Departamento de Salud Pública, Facultad de Medicina, Universidad de La Frontera, Temuco, Chile

${ }^{5}$ Programa Salud Ocupacional, Escuela de Salud Pública, Facultad de Medicina, Universidad de Chile, Santiago, Chile

Acknowledgements The authors would like to thank to employees, managers and venue owners who agreed to participate in this study and also to the Department of Research of the Universidad de Los Andes-Chile for the support given to translate this article.

Contributors JP, PA, AD, SM, CM, NM and VI: substantial contributions to the conception and design of the work on pulmonary function parameters, acquisition, analysis and interpretation of data and final approval of the version to be published; $\mathrm{JP}$ and VI : drafting the work; JP, PA and VI: revising it critically for important intellectual content; Vl: agreement to be accountable for all aspects of the work in ensuring that questions related to the accuracy or integrity of any part of the work are appropriately investigated and resolved.

Funding This study was supported by National Fund for Research and Development in Health FONIS, CONICYT_MINSAL, Research Grant \# SA09I062 and by International Training and Research in Environmental and Occupational Health (ITREOH), Fogarty International Center, NIH Research Grant \#D43TW005746-02

Competing interests The authors have no conflict of interest to declare.

Ethics approval University of Chile School of Medicine's Ethics Committee.

Provenance and peer review Not commissioned; externally peer reviewed.

Data sharing statement № additional data available.

Open Access This is an Open Access article distributed in accordance with the Creative Commons Attribution Non Commercial (CC BY-NC 4.0) license, which permits others to distribute, remix, adapt, build upon this work non-commercially, and license their derivative works on different terms, provided the original work is properly cited and the use is non-commercial. See: http://creativecommons.org/ licenses/by-nc/4.0/

(c) Article author(s) (or their employer(s) unless otherwise stated in the text of the article) 2017. All rights reserved. No commercial use is permitted unless otherwise expressly granted.

\section{REFERENCES}

1. Aceituno P, Iglesias V, Erazo M, et al. [The work environment as a source of exposure to secondhand smoke: a study in workers of bars and restaurants of Santiago, Chile]. Rev Med Chil 2010;138:1517-23.

2. Alwan A, Organization WH. WHO Report on the Global Tobacco Epidemic. Implementing smoke-free environments 2009 http://who. int/tobacco/mpower/2009/gtcr_download/en/index.html (Cited 2016 Jun 24).

3. Bello S, Michalland S, Soto M, et al. Effects in passive smokers of environmental tobacco smoke exposure. Rev Chil Enf Respir 2005;21:179-92.

4. Chan-Yeung M, Dimich-Ward H. Respiratory health effects of exposure to environmental tobacco smoke. Respirology 2003;8:131-9.

5. Collishaw NE, Kirkbride J, Wigle DT. Tobacco smoke in the workplace: an occupational health hazard. Can Med Assoc J 1984;131:1191-204.

6. EPA. Proposed identification of environmental tobacco smoke as a Toxic Air Contaminant. Tobacco Control. Surveys and Program Evaluations from Outside UCSF Paper CALEPA 2005 https://oehha. ca.gov/media/downloads/air/report/app32005.pdf (cited 2017 July 18).

7. Department of Health and Human Services USA. The consequences of smoking on health. 50 years of progress. Report of the US Department of Health and Human Services USA. Executive Summary 2014. 
8. OMS-OPS. Report on tobacco control in the region of the Americas. 10 years of the framework convention of the world health organization for tobacco control. Washington D.C 2016.

9. Allwright S, Paul G, Greiner B, et al. Legislation for smoke-free workplaces and health of bar workers in Ireland: before and after study. BMJ 2006;332:151.

10. Coultas DB. Health effects of passive smoking. 8. Passive smoking and risk of adult asthma and COPD: an update. Thorax 1998;53:381-7.

11. De Vito EL, Rojas RA. [Environmental tobacco smoke]. Medicina 2005;65:545-9.

12. Jaakkola MS, Jaakkola JJ, Becklake MR, et al. Passive smoking and evolution of lung function in young adults. An 8-year longitudinal study. J Clin Epidemiol 1995;48:317-27.

13. Jayet PY, Schindler C, Schwartz J, et al. Passive smoking exposure among adults and the dynamics of respiratory symptoms in a prospective multicenter cohort study. Scand J Work Environ Health 2005;31:465-73.

14. Rizzi M, Sergi M, Andreoli A, et al. Environmental tobacco smoke may induce early lung damage in healthy male adolescents. Chest 2004;125:1387-93.

15. Alipour S, Deschamps F, Lesage FX. Effects of environmental tobacco smoke on respiratory symptoms and pulmonary function. Inhal Toxicol 2006;18:569-73.

16. Chen R, Tunstall-Pedoe $H$, Tavendale R. Environmental tobacco smoke and lung function in employees who never smoked: the Scottish MONICA study. Occup Environ Med 2001;58:563-8.

17. Fidan F, Cimrin AH, Ergor G, et al. Airway disease risk from environmental tobacco smoke among coffeehouse workers in Turkey. Tob Control 2004;13:161-6.

18. Janson C, Chinn S, Jarvis D, et al. European Community Respiratory Health Survey. Effect of passive smoking on respiratory symptoms, bronchial responsiveness, lung function, and total serum $\lg \mathrm{E}$ in the European community respiratory health survey: a cross-sectional study. Lancet 2001;358:2103-9.

19. Eisner MD. Environmental tobacco smoke exposure and pulmonary function among adults in NHANES III: impact on the general population and adults with current asthma. Environ Health Perspect 2002;110:765-70.

20. Künzli N, Schwartz J, Stutz EZ, et al. Association of environmental tobacco smoke at work and forced expiratory lung function among never smoking asthmatics and non-asthmatics. The SAPALDIATeam. Swiss Study on Air Pollution and Lung Disease in Adults. Soz Praventivmed 2000;45:208-17.
21. Benowitz NL. Biomarkers of environmental tobacco smoke exposure. Environ Health Perspect 1999;107(Suppl 2):349-55

22. Tutka P, Mosiewicz J, Wielosz M. Pharmacokinetics and metabolism of nicotine. Pharmacol Rep 2005;57:143-53.

23. Centers for Disease Control and Prevention. National report of human exposure to environmental chemicals. 2017 https://www.cdc. gov/exposurereport/ (Cited 15 Mar 2017).

24. Al-Delaimy WK, Crane J, Woodward A. Questionnaire and hair measurement of exposure to tobacco smoke. J Expo Anal Environ Epidemiol 2000;10:378-84.

25. Al-Delaimy WK. Hair as a biomarker for exposure to tobacco smoke. Tob Control 2002;11:176-82.

26. Iglesias V, Erazo M, Droppelmann A, et al. Occupational secondhand smoke is the main determinant of hair nicotine concentrations in bar and restaurant workers. Environ Res 2014;132:206-11.

27. Salud OMS. "Convenio Marco de la OMS para el control del tabaco". 2013 http://www.who.int/fctc/text_download/es/ (Cited 24 Jun 2016)

28. Muñoz C, Droppelmann A, Erazo $\bar{M}$, et al. Occupational exposure to polycyclic aromatic hydrocarbons: a cross-sectional study in bars and restaurants in Santiago, Chile. Am J Ind Med 2016;59:887-96. Version of record online: 28.

29. Burgos F, Casan P, Del Campo F, et al. SEPAR regulation: forced spirometry. 2013 http://www.ics.gencat.cat/3clics/guies/184/img/guiasepar20131.pdf (Cited 24 Jun 2016).

30. Gutiérrez M, Beroíza T, Barzone G, et al. Spirometry: procedures manual. Chilean society of respiratory diseases, 2006. Rev Chil Enf Respir 2007;23:31-42.

31. Vine MF, Hulka BS, Margolin BH, et al. Cotinine concentrations in semen, urine, and blood of smokers and nonsmokers. Am J Public Health 1993;83:1335-8.

32. Tong IS, Lu Y. Identification of confounders in the assessment of the relationship between lead exposure and child development. Ann Epidemiol 2001;11:38-45.

33. Fahim AE, El-Prince M. Passive smoking, pulmonary function and bronchial hyper-responsiveness among indoor sanitary workers. Ind Health 2012;50:516-20.

34. Wong TW, Wong AH, Lee FS, et al. Respiratory health and lung function in Chinese restaurant kitchen workers. Occup Environ Med 2011;68:746-52.

35. Skogstad M, Kjaerheim K, Fladseth G, et al. Cross shift changes in lung function among bar and restaurant workers before and after implementation of a smoking ban. Occup Environ Med 2006;63:482-7. 